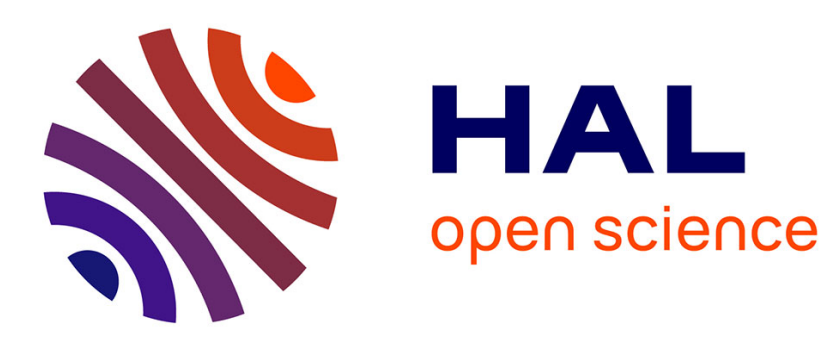

\title{
Enzymic degradation of isolated pectic substances and cell wall from pulp of grape berries
}

\author{
L. Saulnier, J.F. Thibault
}

\section{To cite this version:}

L. Saulnier, J.F. Thibault. Enzymic degradation of isolated pectic substances and cell wall from pulp of grape berries. Carbohydrate Polymers, 1987, 7, pp.345-360. hal-02721307

\section{HAL Id: hal-02721307 \\ https://hal.inrae.fr/hal-02721307}

Submitted on 1 Jun 2020

HAL is a multi-disciplinary open access archive for the deposit and dissemination of scientific research documents, whether they are published or not. The documents may come from teaching and research institutions in France or abroad, or from public or private research centers.
L'archive ouverte pluridisciplinaire HAL, est destinée au dépôt et à la diffusion de documents scientifiques de niveau recherche, publiés ou non, émanant des établissements d'enseignement et de recherche français ou étrangers, des laboratoires publics ou privés. 


\title{
Enzymic Degradation of Isolated Pectic Substances and Cell Wall from Pulp of Grape Berries
}

\author{
Luc Saulnier* and Jean-François Thibault \\ Institut National de la Recherche Agronomique, Centre de Recherches \\ Agro-Alimentaires, Laboratoire de Biochimie et Technologie des Glucides, \\ 44072 Nantes Cedex, France
}

(Received 4 June 1986; accepted 28 November 1986)

SUMMARY

Pectic substances sequentially extracted with water (WSP), oxalate (OXP), acid (HP) and alkali (OHP) from an alcohol-insoluble residue (AIR) from pulp of grape berries, and further purified, were degraded with two pectic enzymes, namely endopolygalacturonase (endopg) and endopectinylase (endopel). Degradation products were fractionated by gel permeation chromatography (Bio-gel P2, Sephadex G100, Sepharose CL $6 B)$ or by ion-exchange chromatography (DEAE-Sephacel). The results suggest that pectic substances from grape berries are constituted of 'smooth' homogalacturonan areas, interspersed with very densely branched 'hairy' regions where neutral sugar side-chains are located. WSP on one hand and HP, OXP, OHP on the other hand were differentiated by their side-chain length. Treatment of AIR previously extracted with water and oxalate by endopel are reported and degradation products are compared with HP 'hairy' fragments.

\section{INTRODUCTION}

Pectic substances are composed of a rhamnogalacturonan backbone in which rhamnosyl residues are interspersed in chains of $\alpha(1-4)$-linked galacturonic acids partly esterified by methanol (Aspinall, 1980; Dey \& Brinson, 1984). Neutral sugars, mainly arabinose and galactose, are found as side chains of varying length (Aspinall, 1980). Rhamnosyl residues are the main branching point of side chains (Albersheim, 1978),

*Present address: INRA, Institut des Produits de la Vigne, Laboratoire des Polymeres et des Techniques Physico-Chimiques, 9 Place Viala, 34060 Montpellier Cedex, France.

Carbohydrate Polymers 0144-8617/87/\$03.50 - (C) Elsevier Applied Science Publishers Ltd, England, 1987. Printed in Great Britain 
but some sugars, such as xylose, may be bound to galacturonic acid residues. These structural features have been established from permethylation analysis of pectin fragments released enzymatically from cell walls and of pectins degraded by mild acid hydrolysis. Other studies, using enzymes as analytical tools on isolated pectins, have led some workers (De Vries et al., 1982; Thibault, 1983a, Rouau \& Thibault, 1984; Rombouts \& Thibault, 1986) to distinguish 'hairy' and 'smooth' regions in the pectin molecule, because side-chains were found to be concentrated on small areas of the rhamnogalacturonan backbone. In this paper, pectic substances sequentially extracted from pulp of grape berries by water (WSP), oxalate (OXP), hot dilute $\mathrm{HCl}$ (HP), and cold dilute $\mathrm{NaOH}(\mathrm{OHP})$ and further purified (Saulnier \& Thibault, 1987) were submitted to endopg and endopel action, which effected hydrolysis of the $\alpha(1-4)$ galacturonic acid bonds and a $\beta$-elimination reaction, respectively. These isolated pectins contained galacturonic acid (63-54\% dry weight) and some neutral sugars (25-17\% dry weight) composed mainly of arabinose and galactose but also of rhamnose, xylose and minor amounts of glucose and mannose, and they were characterized by a high degree of esterification with the exception of OHP. Results were compared to those obtained by the action of endopel on grape berry cell walls.

\section{MATERIALS AND METHODS}

\section{Pectic substances}

An alcohol-insoluble residue (AIR) was prepared from the pulp of grape berries and the pectic substances were sequentially extracted with water (WSP), oxalate (OXP), hot $\mathrm{HCl}(\mathrm{HP})$ and cold $\mathrm{NaOH}(\mathrm{OHP})$, and further purified as previously described (Saulnier \& Thibault, 1987). Samples were dissolved in distilled water prior to enzymic degradation or deesterified as follows. Pectins $\left(2 \mathrm{mg} \mathrm{ml}^{-1}\right)$ were dissolved in $0.05 \mathrm{M} \mathrm{NaOH}$ under magnetic stirring $\left(2 \mathrm{~h}\right.$ at $\left.2^{\circ} \mathrm{C}\right)$, then $\mathrm{pH}$ was adjusted to $5-6$ with $0 \cdot 1 \mathrm{~m} \mathrm{HCl}$ and solutions were extensively dialyzed against distilled water and concentrated under vacuum (at $<40^{\circ} \mathrm{C}$ ) to obtain appropriate concentration.

\section{Enzymes and degradation conditions}

Endopolygalacturonase (endopg, E.C. 3.2.1.15) (Thibault \& Mercier, 1977, 1978) and endopectinylase (endopel, type 2, E.C. 4.2.2.10) (Van Houdenhoven, 1975) were purified from Aspergillus niger preparations. 
Endopg hydrolysis (2 nkat $\left.\mathrm{ml}^{-1}\right)$ was performed, on pectins previously de-esterified, in NaOAc buffer $(0.05 \mathrm{M}, \mathrm{pH} 4.2)$ at $30^{\circ} \mathrm{C}$ for $24 \mathrm{~h}$ (Thibault, 1983a). The extent of hydrolysis was determined by measuring reducing sugars. Degradation of pectins by endopel $(8.3$ nkat $\left.\mathrm{ml}^{-1}\right)$ was performed in citrate buffer $(0.01 \mathrm{M}, \mathrm{pH} 5.2)$ at $30^{\circ} \mathrm{C}$ for $24 \mathrm{~h}$ (Rombouts \& Thibault, 1986) and the reaction was monitored by measuring absorbance at $235 \mathrm{~nm}$ of aliquots diluted tenfold in distilled water and the percentage degradation was calculated using a molar extinction coefficient of 5500 (Edstrom \& Phaff, 1964).

The degradation of the cell wall of grape berries by endopel was performed as follows: AIR ( $4 \mathrm{~g})$ was first sequentially extracted, as described by Saulnier \& Thibault (1987), with water, oxalate and citrate buffer, in order to remove soluble pectic substances (WSP, OXP and citrate-soluble), then the residue was suspended in $200 \mathrm{ml}$ of citrate buffer $(0.01 \mathrm{M}, \mathrm{pH} 5.2)$ under magnetic stirring at $30^{\circ} \mathrm{C}$ and endopel was added ( 4.2 nkat). The degradation was monitored by measuring galacturonic acid content and absorbance at $235 \mathrm{~nm}$ of aliquots periodically removed. After $48 \mathrm{~h}$ the mixture was centrifuged ( $30 \mathrm{~min}, 3000 \mathrm{~g}$ ), the supernatant was concentrated under vacuum (at $<40^{\circ} \mathrm{C}$ ) filtered through a $3 \cdot 0-\mu \mathrm{m}$ Millipore sieve and frozen for subsequent analysis.

\section{Analytical methods}

Galacturonic acid and neutral sugars were determined by automated $m$ phenylphenol (Blumenkrantz \& Asboe-Hansen, 1973; Thibault, 1979) and orcinol (Tollier \& Robin, 1979) methods, respectively (responses were corrected for mutual interferences). Reducing sugars were determined by the method of Nelson (1944) using galacturonic acid as a standard. Neutral sugars were released by TFA hydrolysis $(2 \mathrm{M}, 1.25 \mathrm{~h}$ at $120^{\circ} \mathrm{C}$ ) of pectin fragments, and analyzed by gas-liquid chromatography (GLC) as their alditol acetate derivatives (Selvendran et al., 1979).

\section{Gel permeation chromatography}

Chromatography using Bio-gel P2 was performed as described previously (Thibault, 1980), the product of an enzymic digestion of a pectin $\left(2 \mathrm{mg} \mathrm{ml}^{-1}\right)$ being injected $(0.5 \mathrm{ml})$ onto the column $(203 \mathrm{~cm} \times 2$ $\mathrm{cm})$ and eluted by an NaOAc buffer $\left(0.1 \mathrm{M}, \mathrm{pH} \mathrm{3.6)}\right.$ at $50 \mathrm{ml} \mathrm{h}^{-1}$. The eluate was continuously analyzed for galacturonic acid and neutral sugar content by the $m$-phenylphenol and orcinol methods, respectively.

The proceeds of enzymic digestion of pectins $\left(1-2 \mathrm{mg} \mathrm{ml}^{-1}\right)$ were also injected $(1-2 \mathrm{ml})$ onto columns containing Sephadex G100 $\left(V_{0}: 30 \mathrm{ml}\right.$, $\left.V_{\mathrm{t}}: 84 \mathrm{ml}\right)$, Sepharose CL 6B ( $\left.V_{0}: 43 \mathrm{ml}, V_{\mathrm{t}}: 108 \mathrm{ml}\right)$ and Sepharose CL 
2B $\left(V_{0}: 74 \mathrm{ml}, V_{\mathrm{t}}: 190 \mathrm{ml}\right)$ and were eluted by an NaOAc buffer $(0 \cdot 1 \mathrm{M}$, $\mathrm{pH} \mathrm{4.0)}$ at $15-20 \mathrm{ml} \mathrm{h}^{-1}$. Fractions (3-4 ml) were collected and analyzed for their galacturonic acid and neutral sugar content by the $m$-phenylphenol and orcinol methods, respectively.

The neutral sugar composition of fractions isolated by gel permeation chromatography was determined by aggregating aliquots of concerned fractions. Such aggregates were extensively dialyzed against distilled water, evaporated to dryness and analyzed by GLC.

\section{Ion-exchange chromatography}

Fractions derived from endopg WSP and HP digestions and isolated at the void volume of Sephadex G100 were chromatographed on DEAESephacel. The fractions eluted below $K_{\text {av }} 0 \cdot 2$ on Sephadex G100 were pooled, extensively dialyzed against distilled water and evaporated to dryness below $40^{\circ} \mathrm{C}$, an accurate amount of water was then added and the solution $(1 \mathrm{ml})$ was loaded onto the DEAE column $(7.5 \mathrm{~cm} \times 1.6 \mathrm{~cm})$ and washed with $50 \mathrm{ml}$ of NaOAc buffer $(0.05 \mathrm{M}, \mathrm{pH} 4.8)$. The bound material was eluted using $90 \mathrm{ml}$ of a linear NaOAc buffer gradient $(0.05$ $\mathrm{M}-0.8 \mathrm{M}, \mathrm{pH} 4.8)$. Fractions $(3 \mathrm{ml}$ ) were collected and analyzed for their galacturonic acid and neutral sugar content as described earlier. The neutral sugar compositions of the isolated fractions were determined as for gel permeation products.

\section{RESULTS AND DISCUSSION}

\section{Enzymic degradation of isolated pectins}

\section{Enzymic action}

Prior to degradation by endopg, WSP, OXP and HP were de-esterified in order to maximize hydrolysis, as endopg is unable to cleave linkages between methyl galacturonate residues (Rexova-Benkova \& Markovic, 1976). The de-esterification process was assumed to have no effect on sugar composition (Rouau \& Thibault, 1984; Rombouts \& Thibault, 1986). However, slight losses of arabinose and galactose were observed for WSP ( $81 \%$ and $88 \%$ recovered, respectively). Although the temperature was kept low $\left(2^{\circ} \mathrm{C}\right)$ a decrease in $M_{\mathrm{w}}$ was evident as attested by higher $K_{\mathrm{av}}$ values on Sepharose 2B CL for de-esterified WSP and HP compared to native pectins and probably arose from a $\beta$-elimination reaction during the de-esterification process (Albersheim et al., 1960). The extent of degradation was high $(45 \%, 40 \%, 39 \%$ and $38 \%$ for WSP, 
OXP, HP and OHP, respectively), as compared to sugar-beet pectins (Rombouts \& Thibault, 1986) (range 29.3\% to 35.7\%) but lower than with a commercial polygalacturonic acid (Thibault, 1983b)(57.5\%). The action of endopg is hampered by rhamnosyl residues and neutral sugar side chains, and the high degree of hydrolysis of the four samples shows that substantial homogalacturonan regions are present. WSP, which had the lowest rhamnose content and the highest neutral sugar content (Saulnier \& Thibault, 1987) was more extensively degraded than other samples.

Endopel, which catalyzed the $\beta$-elimination reaction between methylesterified galacturonic residues, was not assayed with OHP since it was de-esterified during the extraction step. WSP, OXP and HP were highly esterified (Saulnier \& Thibault, 1987) $(77 \%$ to $68 \%)$, and the percentages of galacturonosyl bonds broken were similar $(16 \%, 14 \%$ and $18 \%$ for WSP, OXP and HP, respectively) and higher than for sugar-beet pectins (Rombouts \& Thibault, 1986). Endopel is blocked by steric factors and required a certain sequence of methyl-esterified galacturonosyl residues (Rexova-Benkova \& Markovic, 1976; Pilnik \& Rombouts, 1981), which explained the lower extent of degradation than with endopg.

\section{Characterization of degradation products}

Products of enzymic degradation have been submitted to gel permeation chromatography on various supports.

The proceeds of the four digestions of pectin by endopg had similar elution patterns on Biogel P2 (Fig. 1); four peaks were separated. The first one, at the void volume of the column, contained some galacturonic acid residues and all the neutral sugars, which corresponded to side chains and rhamnosyl residues. The others were oligogalacturonides identified as tri-, di- and galacturonic acids. The action of endopg was almost complete and trigalacturonic acid was found to be the most abundant final product (Table 1) as previously reported (Thibault, 1983b). These neutral sugars excluded from the column, were associated with only $7 \%$ of the galacturonic acids for WSP and about $22 \%$ for the other fractions (Table 1). The results obtained were in good agreement with the extents of hydrolysis determined above, and confirmed that side chains were not distributed randomly, but on small areas of the rhamnogalacturonan backbone.

There was a general trend towards separation of the products into two large peaks on Sephadex G100 for digestion by both endopg and endopel (Fig. 2). Large fragments of pectin molecule were isolated at the excluded volume $\left(<K_{\mathrm{av}} 0 \cdot 2\right)$, these populations had equivalent amounts 


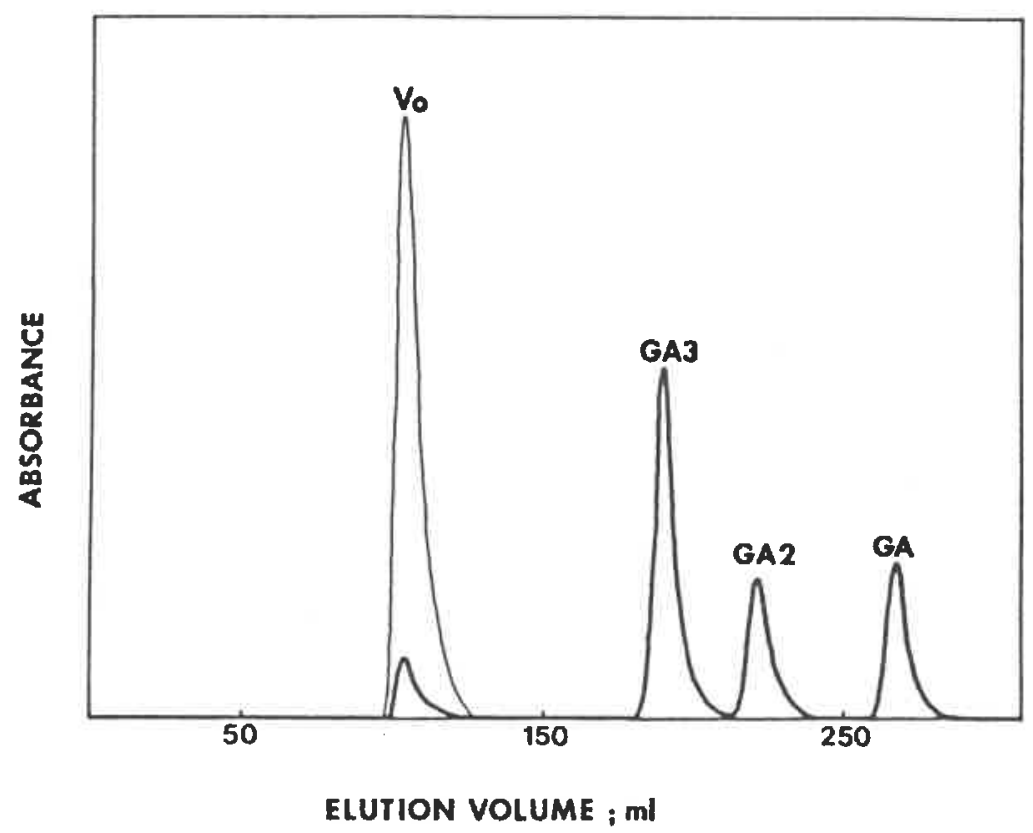

Fig. 1. Elution profiles after chromatography on Bio-gel P2 of WSP, OXP, HP and OHP endopg digestion. $V_{0}$, Void volume; GA3, GA2 and GA peaks corresponding to tri-, di- and galacturonic acid, respectively. (-), Orcinol response for neural sugars (corrected from galacturonic acid response); (-), $m$-phenylphenol response for galacturonic acid.

TABLE 1

Percentage of Galacturonic Acid Detected in Peaks Fractionated on Bio-gel P2 from WSP, OXP, HP and OHP Endopg Digestion ${ }^{a}$

\begin{tabular}{lrrrr}
\hline & $V_{0}$ & $G A 3$ & $G A 2$ & $G A$ \\
\hline WSP & $7 \cdot 0$ & $52 \cdot 8$ & $20 \cdot 2$ & $19 \cdot 8$ \\
OXP & $22 \cdot 3$ & $42 \cdot 6$ & $16 \cdot 9$ & $18 \cdot 2$ \\
HP & $23 \cdot 7$ & $43 \cdot 2$ & $17 \cdot 0$ & $16 \cdot 2$ \\
OHP & $21 \cdot 6$ & $47 \cdot 0$ & $17 \cdot 0$ & $14 \cdot 0$ \\
\hline
\end{tabular}

${ }^{a}$ Results are expressed as $\%$ of total galacturonic acid found in peaks $V_{0}, \mathrm{GA} 3, \mathrm{GA} 2$ and GA.

of galacturonic acid and neutral sugars for OXP, HP and OHP, whereas they were richer in neutral sugars than in galacturonic acid for WSP. The sugar content and composition (Table 2) were similar for digestion by endopg and endopel, and these peaks contained $80 \%$ of the total neutral sugars for all the samples and from $3 \cdot 7 \%$ (WSP) to $15 \%,(\mathrm{HP}, \mathrm{OHP}$ ) of the total galacturonic acid, with an intermediate value of $11 \%$ for OXP. Slight differences in $M_{\mathrm{w}}$ distribution were found for $K_{\mathrm{av}}>0 \cdot 2$, between 


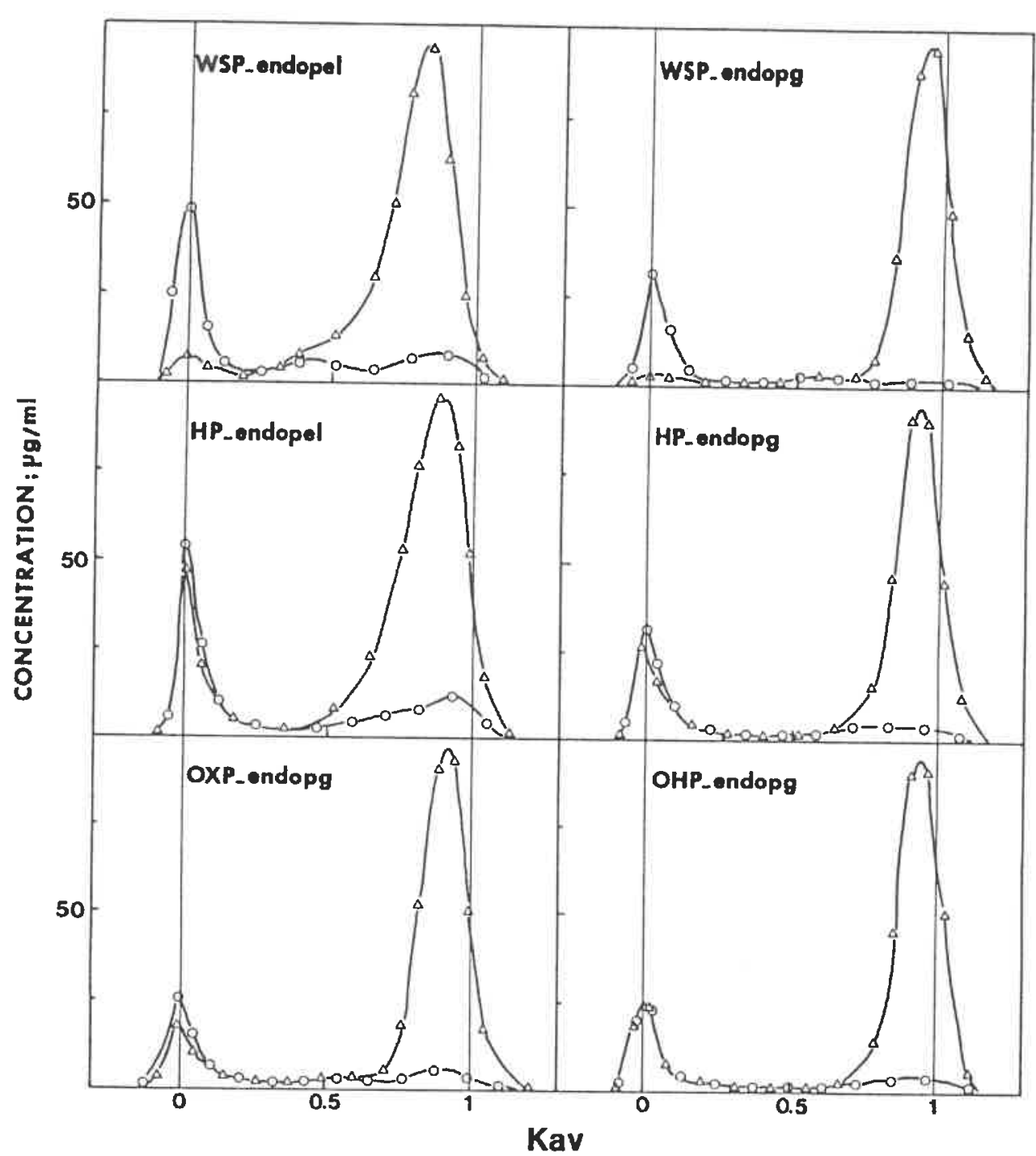

Fig. 2. Elution profiles after chromatography on Sephadex G100 of the degradation products from WSP, OXP, HP and OHP endopg and endopel digestions. - $\triangle-$, anhydrogalacturonic acid; $-\mathrm{O}$, neutral sugars determined by $m$-phenylphenol and orcinol method, respectively.

the products of digestion by endopg and endopel reflecting the different action pattern of the two enzymes. The populations eluted in this fractionation range were composed of small fragments of pectin molecules in which were found the remaining neutral sugars, or of oligogalacturonides which were found close to the total volume.

Sepharose CL 6B separates a population of higher $M_{\mathrm{w}}$ than Sephadex G100. Endopel and endopg digestion gave similar elution patterns (Fig. 3 ) as for those with Sephadex G100. WSP exhibited a peak rich in neutral sugars and poor in galacturonic acid at $K_{\mathrm{av}} 0.45$. The elution pattern for OXP, HP and OHP were closely similar; below $K_{\mathrm{av}} 0 \cdot 7$, the 
TABLE 2

The Sugar Composition and Content of the Products of Digestion with Endopel and Endopg of WSP, OXP, HP and OHP Samples Fractionated on Sephadex G100 and Sepharose CL6B ${ }^{a}$

\begin{tabular}{|c|c|c|c|c|c|c|}
\hline & & & & & $O X P$ & $O H P$ \\
\hline & endopel & endopg & endopel & endopg & & \\
\hline Fracti & recovered $b$ & $v K_{\mathrm{av}} 0 \cdot 2$ & ephadex $G$ & & & \\
\hline$G A^{b}$ & $3 \cdot 7$ & $4 \cdot 2$ & $15 \cdot 0$ & $15 \cdot 2$ & $11 \cdot 0$ & $15 \cdot 7$ \\
\hline $\mathrm{NS}^{b}$ & $82 \cdot 0$ & $82 \cdot 0$ & $83 \cdot 0$ & $80 \cdot 0$ & $82 \cdot 0$ & $67 \cdot 0$ \\
\hline Rha & $7 \cdot 4$ & $6 \cdot 8$ & $28 \cdot 6$ & $24 \cdot 8$ & $28 \cdot 1$ & $32 \cdot 1$ \\
\hline Ara & $42 \cdot 1$ & $42 \cdot 6$ & $36 \cdot 4$ & $38 \cdot 4$ & 33.6 & $21 \cdot 2$ \\
\hline Xyl & $1 \cdot 5$ & $1 \cdot 2$ & $5 \cdot 0$ & $6 \cdot 1$ & $3 \cdot 4$ & $8 \cdot 3$ \\
\hline Man & $0 \cdot 7$ & $1 \cdot 9$ & 0.6 & $1 \cdot 6$ & $1 \cdot 2$ & $0 \cdot 0$ \\
\hline Gal & $42 \cdot 3$ & $44 \cdot 0$ & $20 \cdot 7$ & $21 \cdot 3$ & $20 \cdot 5$ & $23 \cdot 7$ \\
\hline Glc & $5 \cdot 9$ & $3 \cdot 0$ & $7 \cdot 5$ & $3 \cdot 0$ & $13 \cdot 7$ & $14 \cdot 3$ \\
\hline Fracti & ecovered $b$ & $v K_{\mathrm{av}} 0.60$ & pharose $C$ & & & \\
\hline $\mathrm{GA}^{b}$ & $5 \cdot 2$ & $3 \cdot 0$ & - & $16 \cdot 0$ & $10 \cdot 7$ & $20 \cdot 0$ \\
\hline $\mathrm{NS}^{b}$ & $82 \cdot 0$ & $60 \cdot 0$ & - & $71 \cdot 0$ & $80 \cdot 0$ & $81 \cdot 0$ \\
\hline Rha & $7 \cdot 2$ & $7 \cdot 3$ & - & $28 \cdot 9$ & $25 \cdot 2$ & $28 \cdot 0$ \\
\hline Ara & $32 \cdot 3$ & $40 \cdot 2$ & - & $24 \cdot 8$ & $35 \cdot 7$ & $21 \cdot 2$ \\
\hline Xyl & $4 \cdot 2$ & $6 \cdot 0$ & - & $5 \cdot 2$ & $4 \cdot 6$ & $10 \cdot 0$ \\
\hline Man & $3 \cdot 4$ & $2 \cdot 5$ & - & $1 \cdot 0$ & $1 \cdot 0$ & $1 \cdot 0$ \\
\hline Gal & $36 \cdot 8$ & $44 \cdot 7$ & - & $28 \cdot 8$ & $23 \cdot 7$ & $33 \cdot 5$ \\
\hline Glc & $15 \cdot 7$ & $3 \cdot 5$ & - & $11 \cdot 3$ & $9 \cdot 5$ & $6 \cdot 1$ \\
\hline
\end{tabular}

${ }^{a}$ Results are expressed as $\%$ in mole.

$b \%$ in weight of eluted material. GA: galacturonic acid; NS: neutral sugars; determined by the $m$-phenylphenol and the orcinol method, respectively.

ratio of neutral sugars to galacturonic acid was constant $(=1)$. A peak mainly composed of galacturonic acid was eluted close to the total volume. The composition of neutral sugars of the products eluted below $K_{\text {av }} 0.7$ was roughly similar to that found at the void volume of Sephadex G100 (Table 2).

A consistent excess of glucose was observed in all the samples analyzed, which has also been previously reported (Rombouts \& Thibault, 1986); a 'bleeding' of Sephadex gel has been proposed to explain this artifact, but this is not an adequate explanation since we have observed this artifact with Sepharose CL 6B gel which is free from glucose.

The results obtained show that fractions rich in neutral sugar side chains, which have been called 'hairy' regions in previous studies (De 


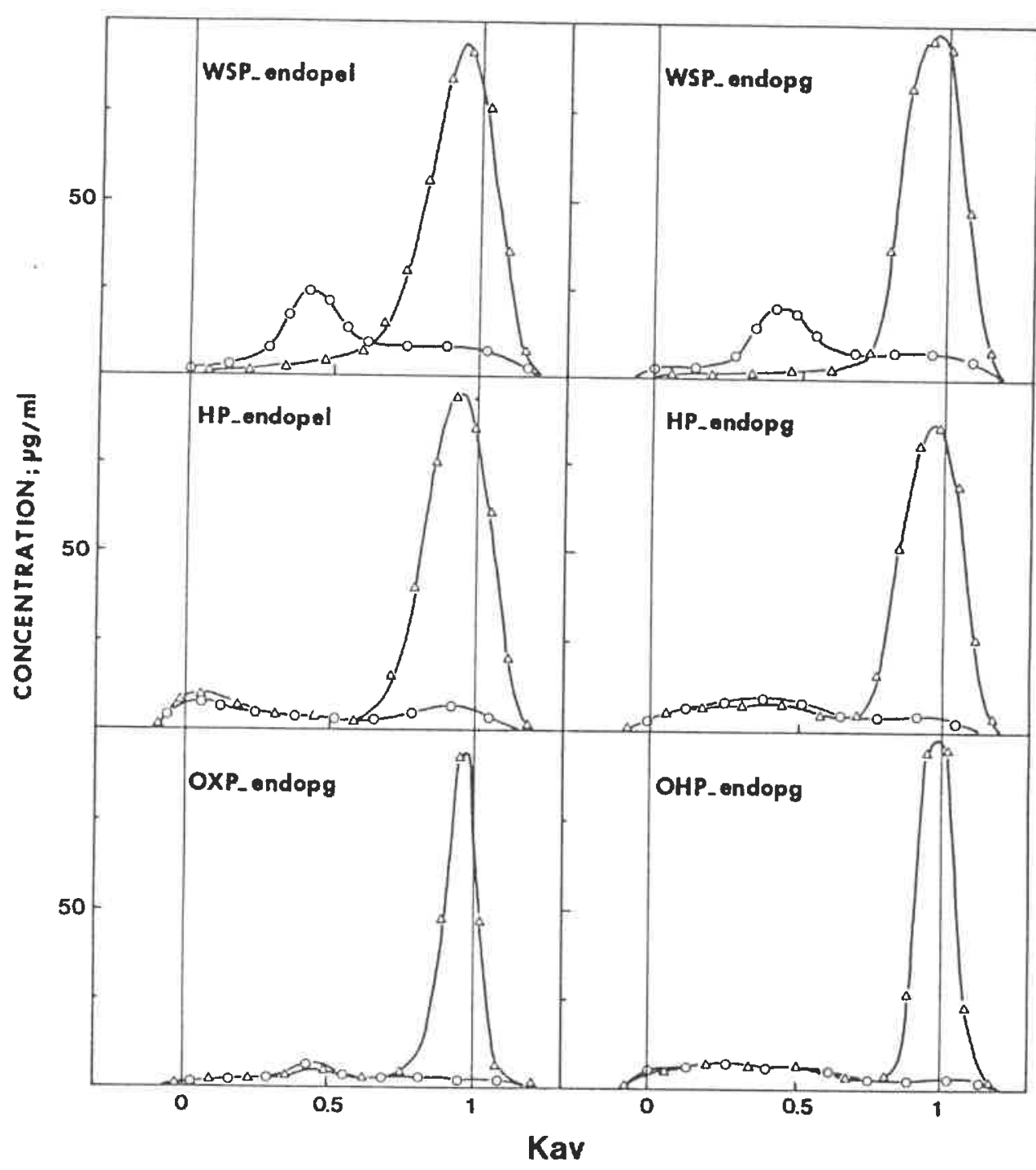

Fig. 3. Elution profiles after chromatography on Sepharose CL $6 \mathrm{~B}$ of the degradation products from WSP, OXP, HP and OHP endopg and endopel digestions. $-\triangle-$, anhydrogalacturonic acid; - - , neutral sugars determined by $m$-phenylphenol and orcinol method, respectively.

Vries et al., 1982; Thibault, 1983a; Rombouts \& Thibault, 1986), are isolated. Endopg and endopel gave the same degradation products with minor differences in galacturonic acid content as reported for sugar-beet pectins (Rombouts \& Thibault, 1986). These 'hairy' fragments seemed to be large molecules, and two main kinds were isolated: on one hand WSP fragments, which were rich in neutral sugars and poor in galacturonic acid and well separated on Sepharose CL 6B; on the other hand OXP, HP and OHP fragments which had equivalent amounts of neutral sugar and galacturonic acid. In subsequent investigations we have studied in greater detail WSP and HP 'hairy' fragments. 


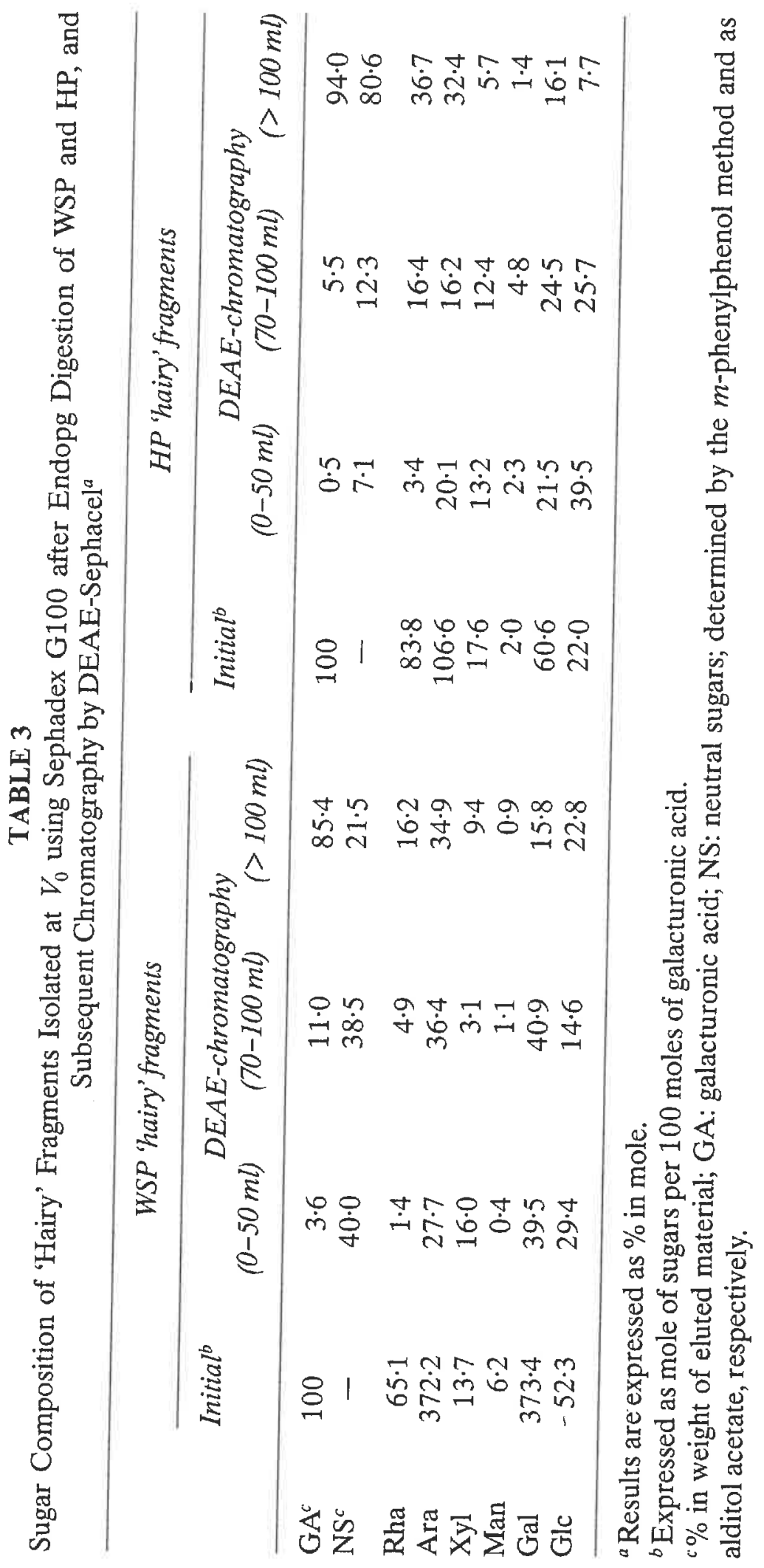




\section{WSP and HP 'hairy' fragments}

The sugar content and composition of WSP and HP fragments eluted at the void volume of Sephadex G100 after digestion by endopg are reported in Table 3. The neutral sugar: galacturonic acid ratio was about 9 for WSP, and the recovery study showed that $55 \%$ of the total rhamnose, $22 \%$ of the total xylose and almost all of the arabinose and galactose of the initial WSP was recovered in these fragments. If we assumed that side chains were mainly arabinogalactans and that all the arabinose and galactose moieties were bound to rhamnosyl residues, a mean degree of polymerization (DP) of 11 is calculated for side chains. HP 'hairy' fragments had a neutral sugar:galacturonic acid ratio of 3 and a mean DP, calculated as above, of 3; no significant enrichment or loss of neutral sugars was found compared to the initial pectins, except for glucose. These results suggested that WSP 'hairy' fragments are composed of small parts of the rhamnogalacturonan backbone with long side chains of arabinogalactan, while HP fragments are larger and composed of a rhamnogalacturonan backbone rich in rhamnose with short side chains.

Both the WSP and HP 'hairy' fragments isolated in the way previously described were chromatographed on DEAE-Sephacel (Fig. 4) and the sugar composition of the eluted peaks was determined (Table 3). Some material, mainly composed of neutral sugars with very low amounts of associated galacturonic acid, was not bound on the column for the two samples, but this material represented $40 \%$ of the total neutral sugars and $3.6 \%$ of the total galacturonic acid for WSP and minor amounts for HP ( $7 \%$ of the neutral sugars and $0.5 \%$ of galacturonic acid). Two peaks were eluted with the acetate buffer gradient for WSP: the first one at low ionic strength was rich in neutral sugars and poor in galacturonic acid; the second one at high ionic strength $(0.6 \mathrm{M})$ was characterized by a neutral sugar:galacturonic acid ratio close to 1 and contained the major part of the overall galacturonic acid content $(85 \%$ of total galacturonic acid). These two peaks were also characterized by an increasing rhamnose content compared to the unbound population (Table 3). The HP fragments were eluted in a mean peak at high ionic strength $(0.6 \mathrm{M})$ of neutral sugar:galacturonic acid ratio close to 1 which contained almost all the galacturonic acid (94\% of total galacturonic acid) and the major part of the neutral sugar $(80 \cdot 6 \%)$. A minor peak was eluted at low ionic strength. Owing to their different galacturonic acid contents and to their hypothetical structure, WSP and HP 'hairy' fragments would have a different elution pattern on ion-exchange chromatography, the first one being, roughly, not bound on the exchanger and the second one eluted 


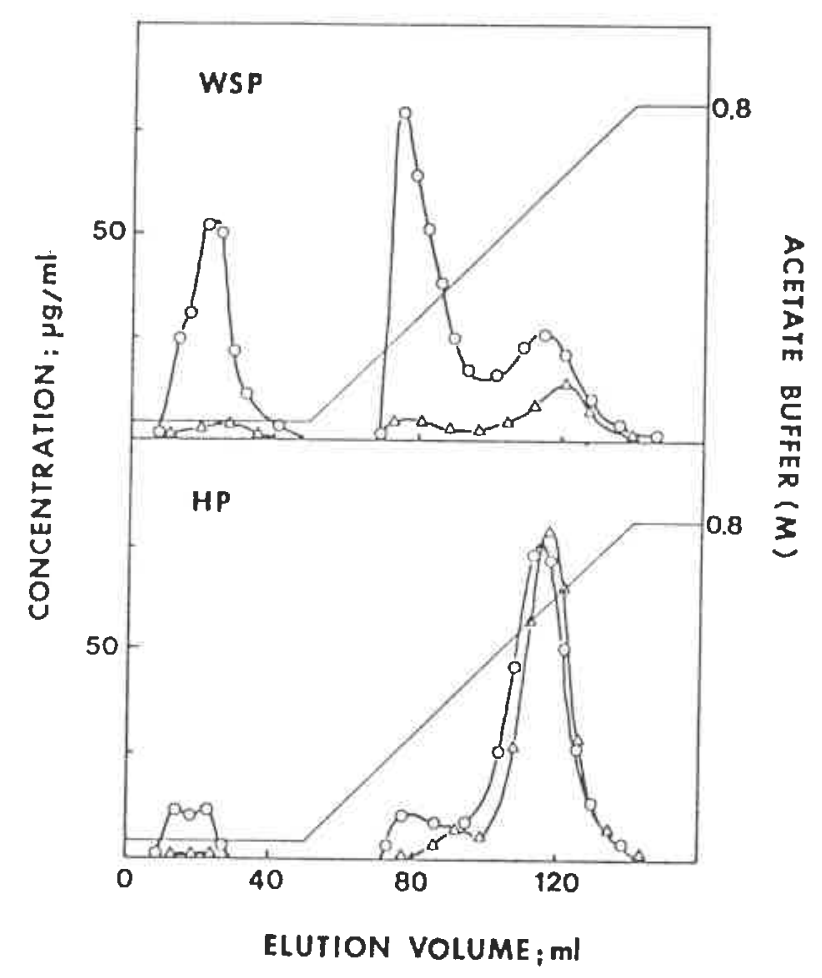

Fig. 4. Elution profiles after chromatography on DEAE-Sephacel of WSP and HP 'hairy' fragments isolated on $V_{0}$ of Sephadex G100 after endopg digestion. $-\triangle-$, anhydrogalacturonic acid; - - , neutral sugars determined by $m$-phenylphenol and orcinol method, respectively.

with an ionic-strength gradient, which was partly observed. Moreover, these results show that the elution on the ion exchanger is affected by the galacturonic acid and the rhamnose content of the fragments which are correlated with the side-chain length.

Although purified pectins were used for enzymic degradation, these materials were highly heterogeneous (Saulnier \& Thibault, 1987), which was reflected in the analyses of the degradation products obtained. WSP 'hairy' fragments which had a relatively homogeneous $M_{\mathrm{w}}$ distribution (Sepharose CL 6B), were highly heterogeneous on ion-exchange chromatography, while HP 'hairy' fragments displayed the opposite behaviour. Nevertheless, a scheme (based on studies of rhamnogalacturonan by Albersheim, 1978) which gives the main structural features of the 'hairy' fragments isolated can be proposed, namely: WSP is composed of a very small portion of rhamnogalacturonan backbone on which long side chains are bound, while HP is composed of large fragments of the rhamnogalacturonan backbone, rich in rhamnose, on which short side chains are bound. It is likely that WSP 'hairy' fragments are a more complex mixture of probably coexisting regions with side 
chains of variable length and composition as reflected by ion-exchange chromatography.

\section{Enzymic degradation of grape-berry cell wall}

Pectins are found in two forms in the AIR. On one hand, some pectic material is soluble in water or in the presence of calcium chelating agents and are extracted apparently without degradation. On the other hand, the main portion of pectic material is insoluble and must be extracted with hot acids (Pilnik \& Voragen, 1970); this extraction involves the degradation of acid-sensitive side chains (arabinans) while the rhamnogalacturonan is only little affected (Be Miller, 1967).

\section{Endopectinylase treatment}

Endopel has been used to release pectic materials from an AIR of apple (Voragen et al., 1980). We have used this enzyme as an alternative to acid treatment after a sequential extraction with water, oxalate and then citrate which was the buffer chosen for the enzyme action. The timecourse of the endopel reaction was followed and a plateau was reached after $24 \mathrm{~h}$ in the conditions used (Fig. 5). The extract was highly esterified and endopel released large amounts of pectic substances, but less than that by an acid treatment $(67 \%$ by weight of the total galacturonic acid released with acid) but more neutral sugars (130\% by weight of the total neutral sugars released by the use of acid) from the AIR. The neutral sugar composition (Table 4) shows that the extract was very rich in arabinose and had similar amounts of rhamnose, xylose and galactose.

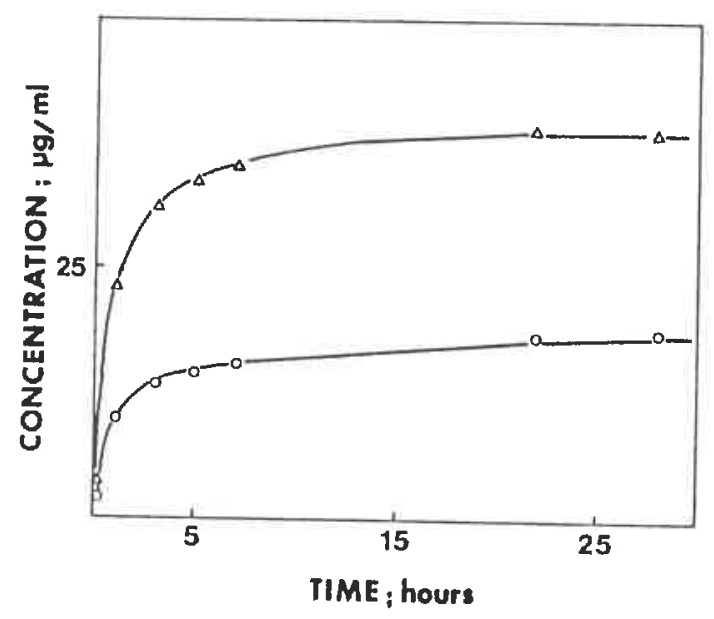

Fig. 5. Time-course of degradation of AIR from pulp of grape berry by endopel. $-\triangle-$, anhydrogalacturonic acid; $-\mathrm{O}-$, neutral sugars determined by $m$-phenylphenol and orcinol method, respectively. 
TABLE 4

Sugar Composition of Endopel AIR Digestion and of Fractions Recovered after Chromatography on Sephadex G100a

\begin{tabular}{lcccc}
\hline & Crude extract & \multicolumn{3}{c}{ Fractions recovered on Sephadex $G 100$} \\
\cline { 3 - 5 } & & $K_{\mathrm{av}}<0 \cdot 2$ & $0 \cdot 2<K_{\mathrm{av}}<0 \cdot 7$ & $K_{\mathrm{av}}>0 \cdot 7$ \\
\hline $\mathrm{GA}^{b}$ & - & $20 \cdot 0$ & $17 \cdot 0$ & $63 \cdot 0$ \\
$\mathrm{NS}^{b}$ & - & $70 \cdot 0$ & $18 \cdot 0$ & $12 \cdot 0$ \\
$\mathrm{Rha}$ & $11 \cdot 5$ & $20 \cdot 4$ & $22 \cdot 1$ & $9 \cdot 0$ \\
Ara & $58 \cdot 0$ & $53 \cdot 7$ & $29 \cdot 9$ & $21 \cdot 3$ \\
Xyl & $11 \cdot 6$ & $2 \cdot 7$ & $14 \cdot 5$ & $20 \cdot 3$ \\
Man & 1.7 & $1 \cdot 3$ & $3 \cdot 5$ & $6 \cdot 2$ \\
Gal & $10 \cdot 4$ & $11 \cdot 8$ & $16 \cdot 0$ & $13 \cdot 5$ \\
Clc & 6.8 & $10 \cdot 1$ & $14 \cdot 0$ & $29 \cdot 7$ \\
\hline
\end{tabular}

${ }^{a}$ Results are expressed in $\%$ of mole.

$b \%$ in weight of eluted material; GA: galacturonic acid, NS: neutral sugars; determined by the $m$-phenylphenol and as alditol acetate, respectively.

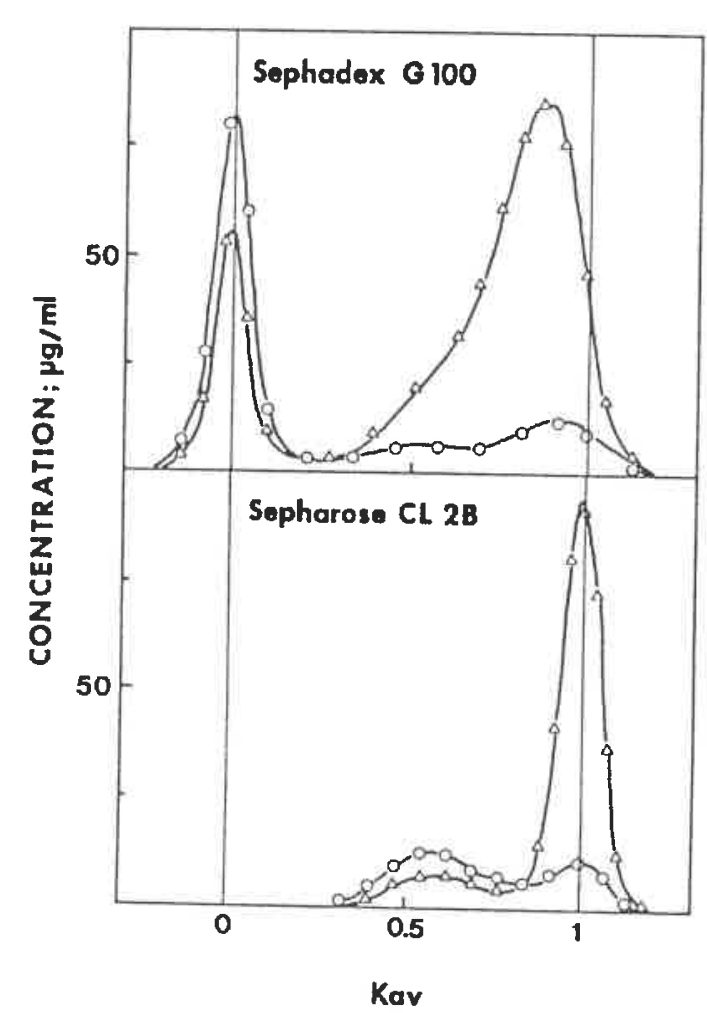

Fig. 6. Elution profiles after chromatography on Sephadex G100 and Sepharose CL $2 \mathrm{~B}$ of the degradation products from endopel AIR digestion. $-\Delta-$, anhydrogalacturonic acid; $-\mathrm{O}-$, neutral sugars determined by $m$-phenylphenol and orcinol method, respectively. 


\section{Analysis of degradation products}

The pectic substances released by endopel were analyzed on Sephadex G100 and Sepharose CL 2B columns (Fig. 6). The large degraded pectin molecules were eluted at the void volume of Sephadex; they were rich in neutral sugars, especially in rhamnose and arabinose (Table 4), and probably corresponded to rich side-chain areas of the rhamnogalacturonan backbone. This fraction had a high $M_{\mathrm{w}}$, and was eluted between $K_{\mathrm{av}}$ 0.3 and 0.8 on Sepharose CL 2B, where $65 \%$ of the neutral sugars and $16 \%$ of the galacturonic acid of the initial material $(w / w)$ was found. Most of the galacturonic acid was eluted close to the total volume on Sephadex and on Sepharose.

The fractions from the endopel cell-wall digestion isolated on Sephadex and Sepharose gels were related to the HP 'hairy' fragments, their neutral sugar compositions were similar, except for the arabinose content which was higher for the endopel than for the HP fragments (Tables 3 and 4). A DP of 3 can be calculated for the endopel fragments isolated at the void volume of Sephadex, which was higher than that for the HP 'hairy' fragments but much lower than that of WSP. Hence it can be presumed that endopel releases HP-type 'hairy' fragments with undegraded arabinans side-chains.

\section{CONCLUSION}

The aim of this paper was to investigate the fine structure of purified pectins with enzymes. The results have shown that pectin molecules are composed of 'smooth' and 'hairy' areas. The WSP and HP pectins are differentiated by their sugar composition and the structure of these regions. Common trends were found between the HP 'hairy' fragments and the pectic substances isolated from the endopel grape cell-wall digestion. It appears from these results that pectin insolubility could be related to the proportion of the 'hairy' regions on the rhamnogalacturonan backbone. We shall investigate further the linkages occurring in side chains by methylation analysis.

\section{ACKNOWLEDGMENTS}

The authors wish to thank Dr F. M. Rombouts (Agricultural University of Wageningen, The Netherlands) for the gift of endopectinylase, and $\mathrm{Dr}$ J.-M. Brillouet (IPV, Montpellier, France) for critical reading of the manuscript. 


\section{REFERENCES}

Albersheim, P., Neukom, H. \& Deuel, H. (1960). Arch. Biochem. Biophys. 90, 46.

Albersheim, P. (1978). In International Review of Biochemistry, Biochemistry of Carbohydrates, Vol. 16, ed. D. J. Manners, University Park Press, Baltimore, pp. 127-50.

Aspinall, G. O. (1980). In The Biochemistry of Plants, Vol. 3, ed. J. Preiss, Academic Press, London and New York, pp. 473-500.

Be Miller, J. N. (1967). In Advances in Carbohydrate Chemistry and Biochemistry, Vol. 22, eds M. L. Wolfrom \& S. Tipson, Academic Press, New York, pp. 25-91.

Blumenkrantz, N. \& Asboe-Hansen, G. (1973). Analyt. Biochem. 54, 484.

De Vries, J. A., Rombouts, F. M., Voragen, A. G. J. \& Pilnik, W. (1982). Carbohyd. Polym. 2, 25.

Dey, P. M. \& Brinson, K. (1984). In Advances in Carbohydrate Chemistry and Biochemistry, Vol. 42, eds S. Tipson \& D. Horton, Academic Press, London and New York, pp. 265-382.

Edstrom, R. D. \& Phaff, H. J. (1964). J. Biol. Chem. 239, 2403.

Nelson, N. (1944). J. Biol. Chem. 153, 375.

Pilnik, W. \& Rombouts, F. M. (1981). In Enzymes and Food Processing, eds. G. G. Birch, N. Blake \& K. J. Parker, Applied Science Publishers, London, pp. 105-28.

Pilnik, W. \& Voragen, A. G. J. (1970). In The Biochemistry of Fruits and their Products, Vol. 1, ed. A. C. Hulme, Academic Press, London and New York, pp. 53-87.

Rexova-Benkova, L. \& Markovic, O. (1976). In Advances in Carbohydrate Chemistry and Biochemistry, Vol. 33, eds S. Tipson \& D. Horton, Academic Press, London and New York, pp. 323-85.

Rombouts, F. M. \& Thibault, J.-F.(1986). Carbohyd. Res. 154, 177.

Rouau, X.\& Thibault, J.-F.(1984). Carbohyd. Polym. 4, 111.

Saulnier, L. \& Thibault, J.-F. (1987). Carbohyd. Polym. 7, 329.

Selvendran, R. R., March, J. F. \& Ring, S. G. (1979). Anal. Biochem. 96, 282.

Thibault, J.-F. (1979). Lebensm.-Wissen. Technol. 12, 247.

Thibault, J.-F. (1980). J. Chromatogr. 194, 315.

Thibault, J.-F. (1983a). Phytochemistry 22, 1567.

Thibault, J.-F.(1983b). Carbohyd. Polym. 3, 259.

Thibault, J.-F. \& Mercier, C. (1977). J. Solid Phase Biochem. 2, 295.

Thibault, J.-F. \& Mercier, C. (1978). J. Food Biochem. 2, 379.

Tollier, M. T. \& Robin, J. P. (1979). Ann. Technol. Agric. 28, 1.

Van Houdenhoven, F. E. A. (1975). Doctoral Thesis, Agricultural University of Wageningen, The Netherlands.

Voragen, A. G. J., Heutink, R. \& Pilnik, W. (1980). J. Appl. Biochem. 2, 452. 